\title{
A internacionalização das revistas científicas e as ações da RICI
}

Caro leitor,

É com satisfação que a Revista Ibero-americana de Ciência da Informação (RICI) lança o número relativo ao primeiro semestre de 2016. A publicação agora alcança o seu nono ano de publicação ininterrupta e, ao meu tempo, o meu primeiro ano à frente da editoria deste periódico.

Nesse meu primeiro ano como editor envidei esforços para que a RICl tivesse maior visibilidade com a indexação nas bases de dados e diretórios internacionais. Assim, foram inscritos e/ou atualizados os registros no Directory of Open Access Journals - DOAJ (URL: doaj.org/toc/1983-5213); no Sistema Regional de Información en Linea para Revistas Cientificas de América Latina, el Caribe, España y Portugal (URL: www.latindex.unam.mx/buscador/ficRev.html?opcion=2\&folio=24828); no Google Scholar (URL: scholar.google.com.br/citations?hl=es\&user=fEcG8jIAAAAJ\&view op=list works); no European Reference Index for the Humanities and Social Sciences - ERIHPLUS (URL: dbh.nsd.uib.no/publiseringskanaler/erihplus/periodical/info?id=487401); no Diretório de Políticas de Acesso Aberto das Revistas Científicas Brasileiras - Diadorin, do Instituto Brasileiro de Informação em Ciência e Tecnologia (URL: diadorim.ibict.br/handle/1/951); na Base de Dados Referencial de Artigos de Periódicos em Ciência da Informação da Universidade Federal do Paraná -- BRAPCI (URL: basessibi.c3sl.ufpr.br/brapci/index.php/journal/view/42), e na Associação Brasileira de Educação em Ciência da Informação - ABECIN (URL: www.abecin.org.br/abecin conteudo.php?id=25).

Também foram feitos registros em sistemas que divulgam os sumários correntes de periódicos, a saber: no Journals for Free -- J4F (ver URL: www.journals4free.com/link.jsp?l=37398937), e no brasileiro Sumários.org (ver URL: www.sumarios.org/).

No período também foram realizados acordos para a divulgação do conteúdo da $\mathrm{RICl}$ pela Sociedad Argentina de Información (SAI), em seu Boletín Informativo Electrónico del Centro de Estudios de Bibliotecología de la Sociedad Argentina de Información (ISSN 1667-

6351), na Seção "Bibliográficas y Webliográficas" (URL:
www.sai.com.ar/bibliotecologia/boletin/ag/bie121.htm). Acerto similar foi realizado com a Asociación Profesional de Archiveros, Bibliotecarios y Documentalistas Madrid (ABDM), em seu Boletin de Noticias de la Asociación ABDM (URL: http://asociacionabdm.org/).

Conforme já tive comentei no editorial anterior (CUNHA, 2015), a RICl, criada em 2008, por meio de um convênio entre uma universidade brasileira (a Universidade de Brasília) e uma espanhola (Universidad Carlos III, de Madrid), procurou, desde a sua gênese promover a aproximação entre pesquisadores e profissionais da Ibero-América e de outras latitudes em prol do desenvolvimento das várias áreas da Ciência da Informação. 
Assim, em consonância com essa missão editorial é que foi reorganizado o conselho editorial da publicação. Na formação da nominata desse novo conselho procurou-se fazer uma distribuição geográfica que pudesse ficar o mais próximo aos ditames da missão editorial. Todos os onze membros do conselho editorial são doutores e vinculados a 10 universidades diferentes de Portugal, Espanha, Brasil, México e Estados Unidos. Todos eles conhecem e possuem enormes ligações com o contexto brasileiro. Os novos membros são:

- Ana Alice Baptista (Universidade do Minho, Departamento de Sistemas de Informação, Portugal);

- Aurora Cuevas (Universidad Complutense, Madrid, Espanha);

- Elmira Luzia Melo Simeão (Universidade de Brasília, Faculdade de Ciência da Informação, Brasil);

- Georgete Medleg Rodrigues (Universidade de Brasília, Faculdade de Ciência da Informação, Brasil, Brasil);

- José Antonio Frías (Universidad de Salamanca, Departamento de Biblioteconomía y Documentación, Espanha);

- José Borbinha (Universidade de Lisboa, Instituto Superior Técnico, Portugal, Portugal);

- Juan José Calva González (Universidad Nacional Autónoma de México, Instituto de Investigaciones Bibliotecológicas y de la Información, México);

- Miquel Térmens Graells (Universidad de Barcelona, Facultad de Biblioteconomía y Documentación, Espanha);

- Ricardo Rodrigues Barbosa (Universidade Federal de Minas Gerais, Escola de Ciência da Informação, Brasil);

- Ruben Urbizagastegui (University of California, Riverside, University Libraries, Estados Unidos);

- Victor Rosenberg (University of Michigan, School of Information, Estados Unidos).

Neste primeiro número de 2016 foram publicados 16 artigos, uma recensão e resumos de teses e dissertações. Os artigos são:

1) "Retos para el bibliotecario académico: MOOC, SIG y Humanidades Digitales como posibilidades para su participación", de Sara Martínez Cardama \& Mercedes Caridad Sebastián. $\mathrm{O}$ artigo analisa a presença e o nível de aplicabilidade do modelo de Biblioteca Integrada a três tendências chaves para a reconfiguração das estruturas bibliotecárias na universidade: os $\mathrm{MOOC}$ ou cursos massivos em linha, os sistemas de informação geográfica e as humanidades digitais. Foi realizada uma análise de conteúdo das páginas web de universidades das 50 primeiras posições no Academic Ranking of World Universities.

2) "Avaliação do Curso de Biblioteconomia da Universidade Federal do Rio Grande FURG: percepção dos discentes", de Rodrigo Aquino de Carvalho, Cintia Kath Blank, Andrei Steveen Moreno, Mauren Porciúncula Moreira da Silva. O trabalho apresenta uma avaliação do curso de Biblioteconomia a partir da visão dos discentes matriculados em 2014.

3) "Uma breve história da automação de bibliotecas universitárias no Brasil e algumas perspectivas futuras", de Michelangelo Mazzardo Marques Viana. O artigo resume a história do desenvolvimento da automação de bibliotecas universitárias do país, desde 
o momento em que os pesquisadores brasileiros começam a disseminar a informática, criando a cultura da automação em instituições de ensino superior. Trata de perspectivas futuras em automação de bibliotecas acadêmicas no Brasil com ferramentas de descoberta, sistemas de próxima geração baseados em nuvem e equipamentos de automação de bibliotecas.

4) "Reconhecimento da biblioteca universitária como um sistema adaptativo complexo (SAC): aplicação do framework GC@BU na Biblioteca Universitária da UFSC", de Roberta Moraes de Bem, Joana Carla de Souza Matta Felício, Maria Bernadete Martins Alves, Sigrid Karyn Weiss Dutra, Tatiana Rossi. Com o apoio do Framework GC@BU a Biblioteca Universitária da UFSC iniciou as atividades de Gestão do Conhecimento em seu âmbito. Neste artigo apresenta-se o resultado do "Reconhecimento da Biblioteca Universitária", que consiste na primeira etapa de aplicação do GC@BU, em que esta é caracterizada como um Sistema Adaptativo Complexo. Constata-se que a aplicação do GC@BU, apresenta resultados positivos, verificando a quão específica, adaptativa e dinâmica é a ferramenta.

5) "Análise multivariada de componentes principais dos fatores que interferem no (não) credenciamento de pesquisadores em programas de pós-graduação", de João de Melo Maricato, Ítala Moreira Alves, Dalton Lopes Martins. A pesquisa tem como objetivos contribuir para o objeto empírico "fatores que interferem no (não) credenciamento de pesquisadores em programas de pós-graduação", e, sobretudo, explorar e compreender as potencialidades do uso da análise multivariada de componentes principais para a análise de dados no campo da ciência da Informação, em especial, nas áreas de bibliometria e da cientometria.

6) "Competência em informação e os contextos educacional, tecnológico, político e organizacional", de Selma Letícia Capinzaiki Ottonicar, Marta Lígia Pomim Valentim, Glória Georges Feres. A presente pesquisa possui a seguinte questão norteadora: como a competência em informação influência nos diferentes contextos sociais? Ressalta-se que foram escolhidos os principais âmbitos de influência a fim de que o leitor possua uma visão amplificada sobre o tema, contudo uma pesquisa que apresente todas as perspectivas de um conhecimento é improvável. Nas considerações finais afirma-se que a competência em informação está presente na política, pois é um fator que permite exercer a cidadania; nas escolas desenvolvendo o aprendizado dos estudantes; além disto, é necessária no manuseio das tecnologias e é uma estratégia de vantagem competitiva nas organizações.

7) "Estudo de viabilidade de rede de bibliotecas em nuvem da administração pública federal direta", de Elaine Coutinho Marcial, Cristine Coutinho Marcial Pinheiro, Maria Elenita M. Nascimento, João Tribouillet Marcial de Menezes. O objetivo geral do estudo é identificar se a Administração Pública Federal Direta está preparada para lidar com a explosão informacional digital por meio do Cloud Computing, assegurando que o registro bibliográfico das publicações oficiais seja preservado, em formato digital, e acessíveis para as gerações futuras.

8) “As concepções teóricas de avaliação de documentos de arquivo na legislação brasileira", de Maria Ivonete Gomes do Nascimento, Eliane Braga Oliveira. A pesquisa 
tem como objetivo mapear a legislação brasileira referente à avaliação de documentos de arquivo e identificar as vertentes teóricas internacionais e nacionais que embasam essa legislação. Observou-se que a teoria do valor, apresentada como critério para a guarda ou a eliminação de documentos e proposta pelos autores norte-americanos Philip Brooks e Theodore Schellenberg, tem predominância conceitual na legislação brasileira.

9) "O papel dos arquivos das instituições federais de ensino superior e a experiência do Arquivo Central da Universidade de Brasília", de Cynthia Roncaglio. O artigo visa a descrever as transformações e apresentar a experiência do Arquivo Central (ACE) da Universidade de Brasília (UnB) referente às estratégias de visibilidade e sensibilização da comunidade universitária para a importância dos arquivos para a administração, ensino, pesquisa e extensão.

10) "Ambientes organizacional e informacional da Cadeia Produtiva de Café", de Lucileide Andrade de Lima do Nascimento, Emir José Suaiden. Analisa o ambiente e fluxos de informação na Cadeia Produtiva de Café (Espírito Santo).

11) "Promoção de competências em informação: formação para iniciação científica no ensino superior e comunidades", de Mônica Regina Peres, Antônio Lisboa Carvalho de Miranda, Elmira Luzia Melo Soares Simeão. Este texto descreve o programa que visa criar um modelo de Competência em Informação sob a ética da multivocalidade. 0 objetivo é desenvolver um modelo de aplicação das competências em informação que possa servir de estimulo à Iniciação Científica.

12) "Organização e tratamento descritivo para registros imagéticos", de Luiz Carlos Flores de Assumpção, André Porto Ancona Lopez, Frank Carlos Lemos Costa. O estudo busca apresentar as formas de descrição de um sistema de arquivos online com registros imagéticos na execução de projetos culturais. Trata-se de uma pesquisa prática com participação direta nos eventos durante a realização do projeto Circuito de Quadrilhas Juninas do Araguaia-Cirquaia-2014.

13) "Prototipagem de banco de dados: o uso da teoria da classificação facetada na modelagem de dados", de Márcio Bezerra da Silva. Objetiva apresentar a aplicação da classificação facetada para organização do conhecimento, visando à recuperação da informação em banco de dados; e de forma específica, investigar a possibilidade de aplicabilidade da classificação facetada com a modelagem de dados em ambientes digitais.

14) "A colaboração científica nas áreas de informação no Brasil (1972-2013) ", de Jayme Leiro Vilan Filho. A colaboração entre cientistas é um indicador relacionado com a produção científica e normalmente ambos podem ser obtidos de bases de dados bibliográficos. Estudos anteriores proporcionaram uma visão da produção e da colaboração científica brasileira nas áreas de informação até 2010 e o presente estudo atualiza as informações sobre estes assuntos até 2013 usando recursos da bibliometria. Foi confirmada a tendência de crescimento da produção de artigos de periódicos e trabalhos de evento. Os gráficos sugerem a existência de correspondência sincrônica entre os dois canais medidos com prevalência de autoria múltipla nos trabalhos de ENANCIB a partir de 2005 e nos artigos de periódicos a partir de 2010. 
15) "A documentação no Brasil: primórdios de sua inserção no país (1895-1920) ", de Carlos Henrique Juvêncio da Silva e Georgete Medleg Rodrigues. O artigo investiga diversas ações de instituições brasileiras que foram tomadas em concordância com as ideias apregoadas pelo Instituto Internacional de Bibliografia, dando destaque às ações da Biblioteca Nacional, do Real Gabinete Português de Leitura e da Biblioteca da Marinha. Evidencia que a inserção da Documentação no Brasil se dá por meio de iniciativas isoladas, contudo, convergindo para a adoção dos ideais de Otlet e La Fontaine nas instituições brasileiras.

16) "Competência em informação dos contadores de histórias conectados em redes no século XXI", de Meri Nádia Marques Gerlin e Elmira Luzia Melo Soares Simeão. A pesquisa utiliza indicadores de perfil e contexto agrupados em um questionário com a finalidade de identificar competências em informação dos narradores do Distrito Federal.

Nesse número também consta uma recensão sobre a obra "Handbook of Research on Comparative Approaches to the Digital Age Revolution in Europe and the Americas", feita pelo pesquisador mexicano Andrés Fernández Ramos.

No presente número estão incluídas as defesas relativas a 2012. Vale a pena ressaltar que, além da referência bibliográfica e dos resumos (português e inglês), também foi incluído o link do documento para o Repositório Institucional da Universidade de Brasília. Assim, o leitor, poderá ter, de forma rápida, acesso ao texto completo da pesquisa realizada no âmbito da nossa pós-graduação.

Desejo uma ótima leitura e até o nosso próximo número!

Murilo Bastos da Cunha

Editor da $\mathrm{RICl}$

\section{Referências}

CUNHA, Murilo Bastos da. A RICl atinge o seu oitavo ano. Revista Ibero-americana de Ciência da Informação, v. 8, n. 2, 2015 . Disponível em: URL: $<$ periodicos.unb.br/index.php/RICl/article/view/16045>. Acessado em: 2 de dezembro de 2015. 